\title{
The Influence of Laparoscopic Sleeve Gastrectomy on Metabolic Syndrome Parameters in Obese Patients in Own Material
}

\author{
Hady Razak Hady • Jacek Dadan • Magdalena Luba
}

Published online: 7 October 2011

(C) The Author(s) 2011. This article is published with open access at Springerlink.com

\begin{abstract}
Popularity of laparoscopic sleeve gastrectomy (LSG) has been growing gradually. The aim of this study was to determine changes in metabolic syndrome parameters as well as insulin, total cholesterol, and LDL cholesterol, and to describe the influence of body weight loss on comorbidities in obese patients after LSG with 1-year followup. The material consists of 130 patients who underwent LSG (2007-2010) in order to treat morbid obesity and who had met before the surgery at least three criteria necessary for the diagnosis of metabolic syndrome according to the International Diabetes Federation. The influence of LSG on comorbidities was also analyzed. During 1-year follow-up after LSG, we obtained a statistically significant decrease in BMI (from $53.18 \pm 7.5 \mathrm{~kg} / \mathrm{m}^{2}$ to $31.4 \pm 3.75 \mathrm{~kg} / \mathrm{m}^{2}, p<0.00001$ ) and a reduction in waist circumference. Twelve months after the surgery, excess weight loss (EWL) was $59.42 \pm 7.21 \%$ and excess body mass index loss (EBL) was $61.03 \pm 6.50 \%$. One year after LSG, the amount of patients with diagnosed metabolic syndrome decreased in 61 patients (53.08\%). After 1 year, none of the patients met five criteria of metabolic syndrome. According to efficiency in body mass loss presented by $\% \mathrm{EWL}$ and $\% \mathrm{EBL}$, LSG is gaining approval as a method of obesity and metabolic syndrome treatment, although it is a relatively new procedure. LSG is rather an easy procedure; the time of performance and hospitalization are shorter which entails normalization in all parameters of metabolic syndrome and decreases the percentage of obese patients with metabolic syndrome.
\end{abstract}

\footnotetext{
H. R. Hady $(\varangle) \cdot$ J. Dadan $\cdot$ M. Luba

1st Department of General and Endocrinological Surgery, University Hospital in Bialystok, Medical University of Bialystok, M.Skłodowskiej-Curie 24A,

15-276 Bialystok, Poland

e-mail: klchirog@umwb.edu.pl
}

Keywords Sleeve gastrectomy $\cdot$ Metabolic syndrome Morbid obesity $\cdot$ Weight loss

\section{Introduction}

Global epidemic of obesity is one of the major health issues in the twenty-first century which influence many aspects of public health, including psychosocial and socio-economic aspects. According to the latest report of WHO, in 2011 the amount of people with BMI $>30$ reaches 0.5 mld which is $10 \%$ of the world population. It is worth noting that almost double increase of percentage of people with morbid obesity has been observed during last 30 years [1]. Correlations between metabolic changes examined for decades finally allowed scientists to define metabolic syndrome-MS (described also as syndrome $\mathrm{X}$, insulin resistance syndrome, deadly quartet) as a coexistence of abdominal obesity, hypertension, accelerated level of glucose, and disorders in lipid management [2-5]. The best known are definitions of World Health Organization from 1998, definition of American Diabetes Association (the most frequently applied and with historical background), and the latest definition of International Diabetes Federation [6-8]. In Poland, in accordance with AHA-NHLBI definition, $23 \%$ of men and $20 \%$ of women meet the criteria for the diagnosis of metabolic syndrome [9]. The results of epidemiological tests indicate significant dissemination of occurrence of metabolic syndrome in USA as well as in Europe. It is estimated that among adult citizens of developed countries, $30-35 \%$ of middle-aged people meet the criteria for the diagnosis of metabolic syndrome [10]. The scale of the problem is illustrated by the fact that patients with diagnosed metabolic syndrome are three times more likely to collapse for a heart attack or stroke and five 
times more likely to develop type 2 diabetes [11-13]. To detain or to decrease the rate of rising amount of patients with metabolic disorders (including obese patients) is now one of the major medical challenges. Currently, in connection with the development of bariatric surgery, which provides long-lasting effects in obesity treatment, it is also reasonable to search for the methods that would not only constantly reduce body mass but would also would normalize lipid management and bring the best therapeutic results in treatment of type 2 diabetes [14]. The popularity of laparoscopic sleeve gastrectomy (LSG), a relatively new bariatric procedure among all surgical methods of treating obesity, has been growing gradually for last 5 years in accordance with long-lasting and promising effects. Hess performed sleeve gastrectomy for the first time in 1988 as part of a duodenal switch (DS) with biliopancreatic diversion (BPD) [15]. Johnston et al. presented this method in 1993 as an isolated technique, and in 1999 the first laparoscopic sleeve gastrectomy was conducted as part of BPD-DS [16, 17]. The procedure is now performed laparoscopically and consists of total gastric resection of the fundus and body from the greater curvature and creation of long, tubular gastric conduit constructed along the lesser curvature of the stomach. Weight loss and improvement in parameters of metabolic syndrome are connected with the resection of the stomach and with following neurohormonal changes. Currently, LSG is recommended as an isolated, definite, and efficient bariatric surgery providing effects not only in morbid obesity treatment but also in improvement of diabetes (DMT2) and metabolic syndrome (MS) [1820]. Due to the fact that $S G$ is one of the youngest methods of treating morbid obesity, there is some kind of a gap in the world literature concerning the influence of this bariatric procedure on parameters of metabolic syndrome and co-morbidities of obesity. The aim of our research is to determine changes in parameters of metabolic syndrome (BMI, blood pressure, glucose concentration, HDL, triglycerides) 1 year after the surgery in 130 obese patients who underwent sleeve gastrectomy. The influence of LSG on insulin, and total and LDL cholesterol concentration in plasma of obese patients and the influence of reduction in body mass on co-morbidities were also analyzed.

\section{Materials and Methods}

The material consists of 130 patients hospitalized in our department from 2007 to 2010 who underwent laparoscopic sleeve gastrectomy (LSG) in order to treat morbid obesity and who had met before the surgery at least three criteria necessary for the diagnosis of metabolic syndrome according to the International Diabetes Federation (visceral obesity BMI $>30 \mathrm{~kg} / \mathrm{m}^{2}$, hypertriglyceridemia $\geq 150 \mathrm{mg} / \mathrm{dl}$, low HDL cholesterol $\mathrm{M}<40 \mathrm{mg} / \mathrm{dl} \mathrm{W}<50 \mathrm{mg} / \mathrm{dl}$, hypertension $\mathrm{RR} \geq$ $130 / 85 \mathrm{mmHg}$, fasting hyperglycemia $\geq 100 \mathrm{mg} / \mathrm{dl}$, or earlier recognized type 2 diabetes). In order to determine the influence of LSG on the level of metabolic syndrome reduction in obese patients in early postoperative period, we limited the observation period (follow-up) to 1 year. In the examined group, qualified for LSG were 72 women (average age $48.73 \pm 9.5$ years) and 58 men (average age $46.19 \pm 9.6$ years). Average body mass in women was $139.2 \pm 21.8 \mathrm{~kg}$ and was slightly lower than in men$149.4 \pm 24.28 \mathrm{~kg}$. Preoperative BMI in both groups was $53.18 \pm 7.8 \mathrm{~kg} / \mathrm{m}^{2}$; among women it was $51.39 \pm 6.7 \mathrm{~kg} / \mathrm{m}^{2}$ and in men it was $55.06 \pm 8.3 \mathrm{~kg} / \mathrm{m}^{2}$. Waist circumference was at an average level of $122.8 \pm 18.4 \mathrm{~cm}$ in women and $134.2 \pm 27.6 \mathrm{~cm}$ in men (Table 1).

Among the criteria we adopted, all examined patients before the qualification for LSG had met at least three criteria necessary for the diagnosis of metabolic syndrome according to the International Diabetes Federation (IDF) $(100 \%)$. Seventy-four patients $(56,92 \%)$ met four criteria for MS and 32 patients $(24.61 \%)$ met five criteria for the diagnosis of metabolic syndrome (Fig. 1).

Among all available bariatric procedures, the choice of LSG was dictated by the following indications: BMI $>50$ and three criteria for metabolic syndrome or BMI $<50$ and four to five criteria for MS, age $>40$ or $<40$ but with three co-morbidities. Laparoscopic sleeve gastrectomy has become the method of choice for these patients according to the criteria mentioned above. Patients qualified for surgical treatment have been controlled for co-morbidities in order to establish appropriate preoperative treatment. Before the surgery, the majority of patients had suffered from sleep apnea (61 patients, 46.92\%); hypertension occurred in 59 patients $(53.07 \%)$, type 2 diabetes in 41 patients $(31.53 \%)$, depressive disorders in 39 patients (30\%), and chronic obstructive pulmonary disease (COPD) in 38 patients (29.23\%); coronary artery disease was diagnosed in 21 patients $(16.15 \%)$, cholelithiasis in 19 patients $(14.61 \%)$, and varicose veins in 17 patients (13.07\%). The occurrence of all co-morbidities observed in the examined group before the surgery is presented in Table 4. Patients were consulted preoperatively by an endocrinologist, diabetologist, and psychologist, and women by a gynecologist. Biochemical

Table 1 Age, waist circumference, body mass, and BMI obese patients in own material

\begin{tabular}{lll}
\hline & Women & Men \\
\hline Age (years) & $48.93 \pm 9.5$ & $46.19 \pm 9.6$ \\
Waist circumference $(\mathrm{cm})$ & $122.8 \pm 18.4$ & $134.2 \pm 27.6$ \\
Body mass $(\mathrm{kg})$ & $139.2 \pm 21.8$ & $149.4 \pm 24.28$ \\
BMI $\left(\mathrm{kg} / \mathrm{m}^{2}\right)$ & $53.18 \pm 7.5$ & $55.06 \pm 8.3$ \\
\hline
\end{tabular}


Fig. 1 The amount of patients who met three, four, or five criteria for the diagnosis of metabolic syndrome

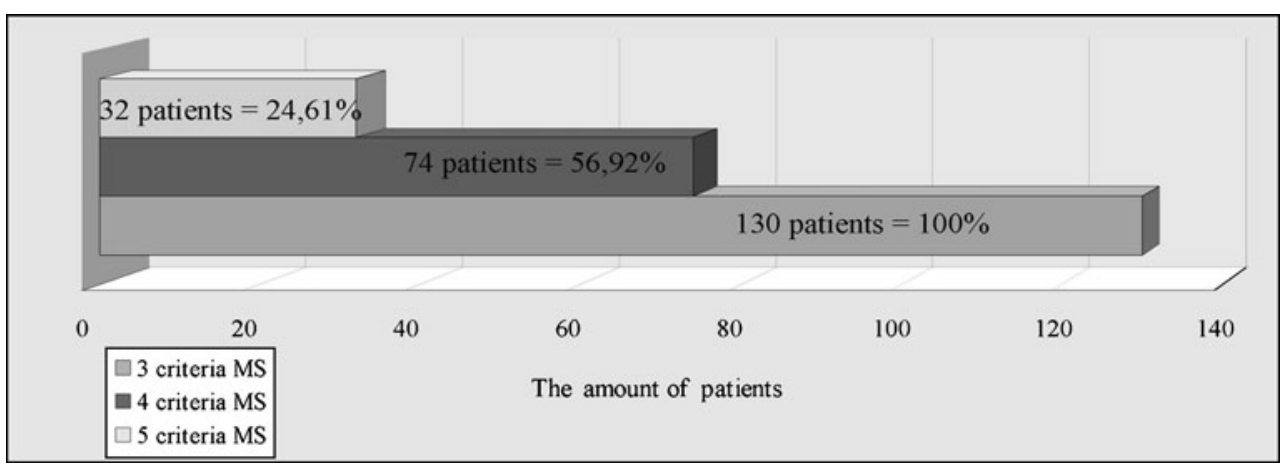

tests were performed: glucose, insulin, triglycerides, total cholesterol, and HDL and LDL cholesterol. The results are presented in Table 2.

Medical imaging was also performed (chest X-ray, abdominal USG, and gastroscopy) in order to exclude possible pathologies of the gastrointestinal tract. Echocardiography was conducted in patients with coronary artery disease or in patients after heart attack. In patients with the risk of occurrence of venous thromboembolism, Doppler ultrasonography of lower limb veins was conducted. In patients with COPD or in cases of suspected sleep apnea, polysomnography or rhinomanometria was performed.

One panel of surgeons (one operator and two assistants) performed all procedures laparoscopically. LSG began with precise examination of the stomach and localization of crow's foot. Using a harmonical knife or LigaSure ${ }^{\circledR}$, gastrocolic omentum was cut next to the wall of the stomach and in the middle of gastrocolic omentum vessels. Cut-off line of the omentum reached upwards to the left diaphragmatic branch and downwards approximately 4$6 \mathrm{~cm}$ from the pylorus. The first charge separated greater curvature towards the crow's foot, and the following charges separated the curvature along the body of the stomach to the angle of His. Possible bleeding from the cutoff line was preserved immediately with coagulation or by hematostatic stitch. The stomach was reduced to the narrow tube with a diameter of $35 \mathrm{~F}$; tightness was checked by methylene blue test. Finally, the drain near the cut-off line was placed. The surgery lasted approximately $64 \mathrm{~min}$. Patients were discharged home in the second or third day

Table 2 Preoperative values of examined parameters

\begin{tabular}{lc}
\hline Insulin $(\mu \mathrm{U} / \mathrm{l})$ & $44.8 \pm 25.82$ \\
Glucose $(\mathrm{mg} / \mathrm{dl})$ & $149.9 \pm 58.54$ \\
Total cholesterol $(\mathrm{mg} / \mathrm{dl})$ & $218.05 \pm 17.61$ \\
Triglycerides $(\mathrm{mg} / \mathrm{dl})$ & $172.3 \pm 48.8$ \\
LDL cholesterol $(\mathrm{mg} / \mathrm{dl})$ & $148.42 \pm 35.5$ \\
HDL cholesterol $(\mathrm{mg} / \mathrm{dl})$ & $42.48 \pm 10.15$ \\
HOMA-IR & $13.2 \pm 11.8$ \\
\hline
\end{tabular}

after the surgery and were under the control of a clinical dietician and out-patient clinic. Generally, a low-calorie diet was recommended. During the first 2 weeks, a low-sodium, semi-liquid diet was advised with the continuance of lowfat and low-carbohydrate diet.

All patients were examined 1, 3, and 6 months and 1 year after the surgery. Fasting 10-12 h since last meal, blood was taken for a clot tube and then centrifuged until serum was obtained. Insulin, glucose, total cholesterol, HDL cholesterol, LDL cholesterol, and triglycerides were evaluated in order to control changes in particular time points after the surgery. Rates of \% EWL, \%EBL, and HOMA-IR, calculated according to the following formula: HOMA $-\mathrm{IR}=\{\operatorname{insulin}[\mu \mathrm{U} / \mathrm{ml}] \times$ glucose (fasting) $[\mathrm{mmol} / \mathrm{l}]\} 22.5$, were considered to be accurate. Evaluation of \%EWL and \%EBL was prepared based on data from 2007. Statistical analysis was prepared using Statistics 6 software for Windows. Values of $p<0.05$ were found statistically significant.

\section{Results}

According to the analysis of obtained material, it is possible to state that 1 month after LSG, a statistically significant $(p<0.01)$ decrease in BMI $\left(45.70 \pm 7.8 \mathrm{~kg} / \mathrm{m}^{2}\right)$ was observed in comparison to preoperative period (53.18 $7.5 \mathrm{~kg} / \mathrm{m}^{2}$ ). Six-month and 1-year follow-up confirmed further statistically significant $(p<0.0001)$ decreases in BMI $\left(31.4 \pm 3.75 \mathrm{~kg} / \mathrm{m}^{2}-1\right.$ year after the surgery). The greatest decrease was observed between the third and sixth month after the surgery $\left(7.1 \mathrm{~kg} / \mathrm{m}^{2}\right)$ (Fig. 2).

During 1-year follow-up, the decrease of body mass excess weight loss (EWL) and BMI excess body mass index loss (EBL) was observed. One month after the LSG, the percentage of weight loss was statistically significant and was equal to $22.34 \pm 3.85 \%$. One year after the surgery, EWL reached $59.42 \pm 7.21 \%$. The reduction in BMI was gradually improving and in every time point remained statistically significant. In the first month after surgical treatment, a statistically significant $(p<0.0001)$ decrease in 
Fig. 2 Postoperative changes in BMI in 130 patients at 1-year follow-up

\begin{tabular}{|c|c|c|c|c|}
\hline $\begin{array}{c}\text { Before the } \\
\text { surgery }\end{array}$ & 1 month & 3 month & 6 month & 12 month \\
\hline $53,18 \pm 7,5$ & $\begin{array}{c}45,7 \pm 7,8 \\
\mathrm{p}<0,01\end{array}$ & $\begin{array}{c}42,5 \pm 5,9 \\
\mathrm{p}<0,0001\end{array}$ & $\begin{array}{c}35,4 \pm 4,9 \\
\mathrm{p}<0,00001\end{array}$ & $\begin{array}{c}31,4 \pm 3,75 \\
\mathrm{p}<0,00001\end{array}$ \\
\hline
\end{tabular}

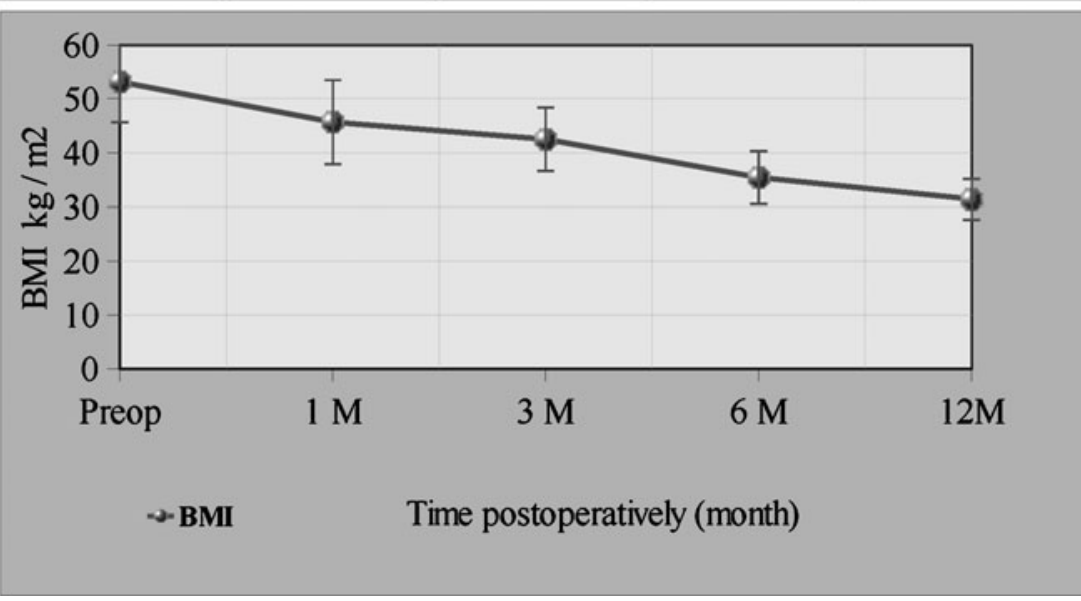

BMI was observed-24.52 $\pm 5.19 \%$. At 1-year follow-up, EBL in examined group of patients reached the level of $61.03 \pm 6.50 \%$ (Figs. 3 and 4 ).

Changes in patients' waist circumference after LSG have also been analyzed, differentiating men from women. The results remained statistically significant in every stage of observation. After 1 year, waist circumference in women decreased from $122.8 \pm 18.4 \mathrm{~cm}$ to $89 \pm 8.2 \mathrm{~cm}$ and in men from $134.2 \pm 27.6 \mathrm{~cm}$ to $106 \pm 9.66 \mathrm{~cm}$ (Fig. 5).

During 1-year postoperative observation, statistically significant changes in insulin concentration in plasma have been observed in every stage of observation in comparison to preoperative values $(44.8 \pm 25.82 \mathrm{IU} / \mathrm{l})$. Changes in concentration of insulin are presented in Table 3. All results of glucose concentration also appeared statistically significant with a tendency to decrease in comparison to preoperative values $(149.9 \pm 58.54 \mathrm{mg} / \mathrm{dl})$. The greatest reduction in concentration of glucose in serum was observed $(105.9 \pm 12.8 \mathrm{mg} / \mathrm{dl}) 1$ month after the surgery; however, the results were statistically significant in every stage $(p<0.05)$. Beneficial correlations between glucose, insulin, and BMI reduction were observed. Our research indicates that the value of HOMA-IR was statistically significant in every stage of observation of patients after
Fig. 3 Percentage of weight loss (\%EWL) after LSG in 130 patients at 1-year follow-up

\begin{tabular}{|c|c|c|c|c|}
\hline & 1 month & 3 month & 6 month & 12 month \\
\hline \%EWL & $22,34 \pm 3,85$ & $32,5 \pm 4,8$ & $48,5 \pm 6,6$ & $59,42 \pm 7,21$ \\
& $\mathrm{p}<0,001$ & $\mathrm{p}<0,00001$ & $\mathrm{p}<0,0001$ & $\mathrm{p}<0,00001$ \\
\hline
\end{tabular}

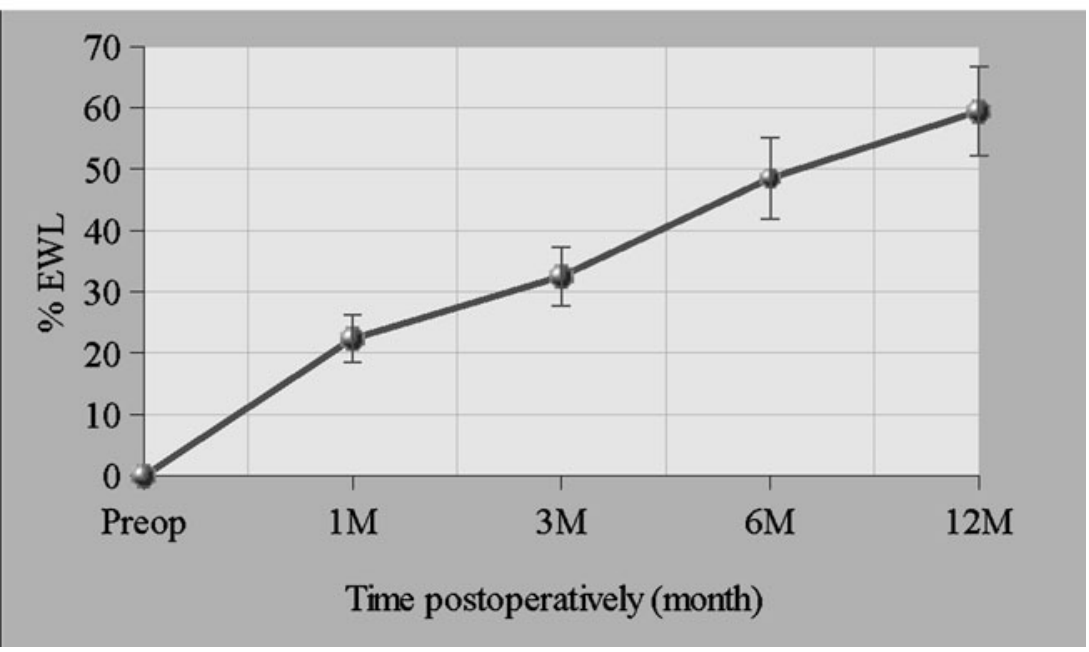


Fig. 4 Percentage of BMI decrease $(\% \mathrm{EBL})$ after LSG in 130 patients at 1 -year follow-up

\begin{tabular}{|c|c|c|c|c|}
\hline & 1 month & 3 month & 6 month & 12 month \\
\hline \%EBL & $\begin{array}{c}24,52 \pm 5,19 \\
\mathrm{p}<0,0001\end{array}$ & $\begin{array}{c}36,44 \pm 6,5 \\
\mathrm{p}<0,00001\end{array}$ & $\begin{array}{c}51,20 \pm 7,08 \\
\mathrm{p}<0,0001\end{array}$ & $\begin{array}{c}61,03 \pm 6,50 \\
\mathrm{p}<0,00001\end{array}$ \\
\hline
\end{tabular}

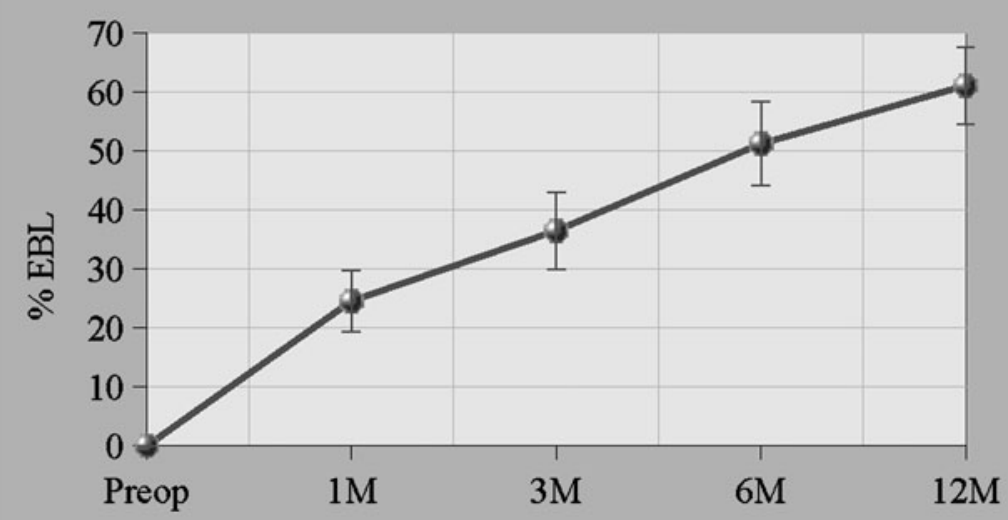

Time postoperatively (month)
LSG. After 1 year, its value decreased from $13.20 \pm 11.8$ to $3.02 \pm 1.98$ (Table 3).

After the analysis of postoperative results in 130 patients after LSG, a beneficial effect of the surgery on all components of the lipid profile was observed. Considering total cholesterol concentration, we observed a statistically significant decrease of its value only just 3 months after the surgery. In the first month, reduction of cholesterol was statistically insignificant; however, between the third and sixth month, the decrease has stopped and remained on the same level. Further decrease has been observed since the sixth month after the surgery. During the examination of triglycerides concentration, we stated a statistically significant decrease of its value after 1 month $(125.7 \pm 24.6 \mathrm{mg} / \mathrm{dl})$, after 3 months $(119.5 \pm 20.5 \mathrm{mg} / \mathrm{dl})$, and after 1 year $(90.65 \pm 25.11 \mathrm{mg} / \mathrm{dl})$ in comparison to the preoperative value $(172.3 \pm 48.8 \mathrm{mg} / \mathrm{dl})$. Only a slight decrease in
Fig. 5 Postoperative changes in waist circumference in 130 patients at 1-year follow-up

\begin{tabular}{|c|c|c|c|c|c|}
\hline & $\begin{array}{c}\text { Before the } \\
\text { surgery }\end{array}$ & 1 month & 3 month & 6 month & 12 month \\
\hline $\mathbf{M}$ & $134,2 \pm 27,6$ & $\begin{array}{c}127,4 \pm 21,1 \\
\mathrm{p}<0,01\end{array}$ & $\begin{array}{c}121,3 \pm 17,6 \\
\mathrm{p}<0,01\end{array}$ & $\begin{array}{c}115,85 \pm 16,2 \\
\mathrm{p}<0,01\end{array}$ & $\begin{array}{c}106,0 \pm 9,66 \\
\mathrm{p}<0,01\end{array}$ \\
\hline W & $122,8 \pm 18,4$ & $\begin{array}{c}115,6 \pm 16,2 \\
\mathrm{p}<0,01\end{array}$ & $\begin{array}{c}110,8 \pm 12,2 \\
\mathrm{p}<0,01\end{array}$ & $\begin{array}{c}97,36 \pm 11,8 \\
\mathrm{p}<0,01\end{array}$ & $\begin{array}{c}89,0 \pm 8,2 \\
\mathrm{p}<0,01\end{array}$ \\
\hline
\end{tabular}

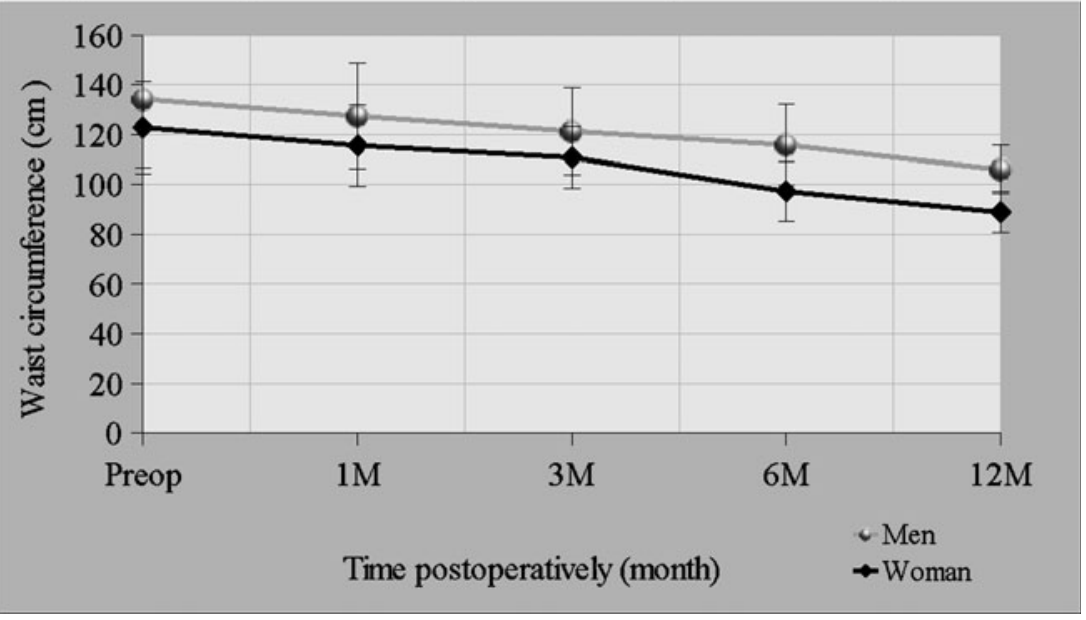


Table 3 Postoperative changes in insulin concentration, glucose level, and HOMA-IR

\begin{tabular}{lccccccc}
\hline & 1 month & $p$ value & 3 months & $p$ value & 6 months & $p$ value & 12 months \\
\hline Insulin & $20.1 \pm 15.4$ & $<0.01$ & $16.1 \pm 12.2$ & $<0.01$ & $15.2 \pm 8.4$ & $<0.05$ & $13.11 \pm 5.25$ \\
Glucose & $105.9 \pm 12.8$ & $<0.05$ & $101.55 \pm 10.1$ & $<0.01$ & $98.5 \pm 6.2$ & $<0.05$ & $91.76 \pm 6.8$ \\
HOMA-IR & $4.4 \pm 3.4$ & $<0.001$ & $4.02 \pm 3.2$ & $<0.01$ & $3.66 \pm 2.48$ & $<0.01$ & $3.02 \pm 1.98$ \\
\hline
\end{tabular}

HDL cholesterol was observed 6 months after the surgery $(43.3 \pm 8.8 \mathrm{mg} / \mathrm{dl})$ in comparison to the preoperative value $(42.48 \pm 10.15 \mathrm{mg} / \mathrm{dl})$. Examination of HDL cholesterol 1 month and 3 months after LSG showed a slight decrease of its concentration in serum in comparison to preoperative values. Taking into consideration the concentration of triglycerides, the decrease has stopped on the same level during the whole observation period. The greatest decrease was observed 1 month after the surgery $(125.7 \pm 24,6 \mathrm{mg} / \mathrm{dl})$ (Fig. 6).

\section{Co-morbidities}

Among 41 patients with type 2 diabetes, 22 demonstrated complete recovery and in 19 patients a significant improvement was observed. In 12 patients, it resulted in halving the daily dose of insulin and seven patients turned insulin therapy to oral hypoglycemic drugs. In 38 patients (55.07\%), a significant improvement of hypertension was observed. According to surgical treatment, in 20 patients it was possible to reduce application of antihypertensive drugs from three to one. In 18 patients, three previously applied medications were replaced by two due to normalization in blood pressure. Bariatric procedures also allowed to reduce drug doses for patients with COPD noticed preoperatively (Table 4).

Among other co-morbidities cured after bariatric procedure (LSG), the following have to be mentioned: sleep apnea (improvement in $36.06 \%$ patients) and depressive disorders (improvement in $17.94 \%$ patients). After bariatric procedure, five of six patients with osteoarthritis were qualified to hip endoprosthesis implantation, and three patients were qualified to knee prosthesis implantation which was not possible preoperatively but could surely improve their quality of life.

In 11 patients, LSG and cholecystectomy were performed simultaneously in order to cure cholelithiasis. Additional improvement has been obtained in following co-morbidities: ulceration and thrombophlebitis. It was a result of conservative treatment applied before the surgery which was also a requirement during qualification for bariatric operation.

During 1-year follow-up, we observed severity of symptoms in two co-morbidities: GERD and esophagitis. The amount of patients with GERD symptoms after LSG
Fig. 6 Postoperative changes in lipid profiles

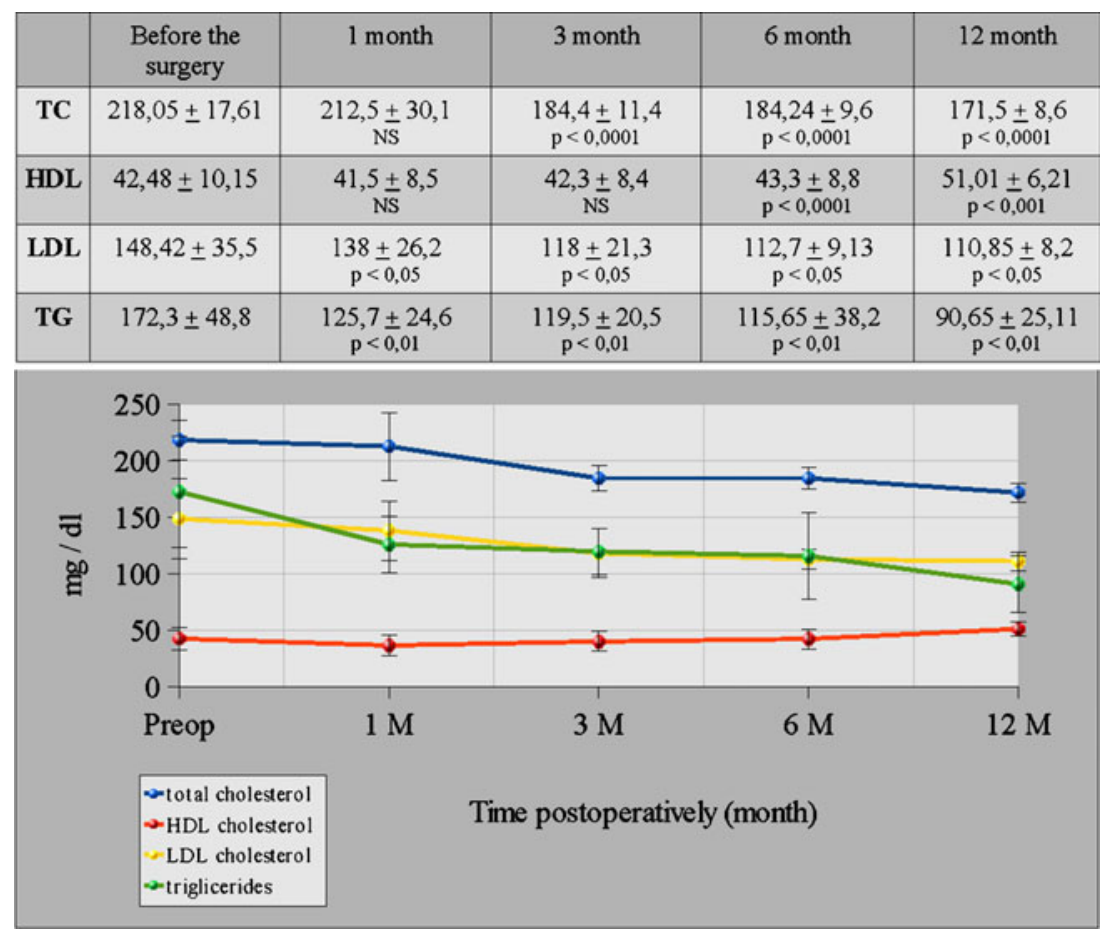


Table 4 Improvement in co-morbidities 1 year after LSG

\begin{tabular}{|c|c|c|c|c|c|c|}
\hline \multirow[t]{2}{*}{ Co-morbidities } & \multicolumn{2}{|c|}{ Before surgical treatment } & \multicolumn{2}{|c|}{ Improvement after 1 year } & \multicolumn{2}{|l|}{ Recovery } \\
\hline & Amount & $\%$ & Amount & $\%$ & Amount & $\%$ \\
\hline Hypertension & 59 & 53.07 & 38 & 55.07 & & \\
\hline Sleep apnea & 61 & 46.92 & 39 & 63.93 & 22 & 36.06 \\
\hline Type 2 diabetes & 41 & 31.53 & 19 & 46.34 & 22 & 53.66 \\
\hline Depressive disorders & 39 & 30.00 & 10 & 25.64 & 7 & 17.94 \\
\hline $\begin{array}{l}\text { Chronic obstructive } \\
\text { pulmonary disease }\end{array}$ & 38 & 29.23 & 25 & 65.79 & & \\
\hline Coronary artery disease & 21 & 16.15 & 8 & 6.15 & & \\
\hline Cholelithiasis & 19 & 14.61 & & & & \\
\hline Spinal disc herniation & 19 & 14.61 & 19 & 100.00 & & \\
\hline Varicose veins & 17 & 13.07 & 8 & 47.05 & & \\
\hline Peptic ulcer disease & 11 & 8.46 & & & & \\
\hline Hemorrhoids & 9 & 6.92 & 2 & 22.22 & & \\
\hline Crus ulcer & 6 & 4.61 & 4 & 66.66 & & \\
\hline Hip osteoarthritis & 6 & 4.61 & & & 5 & \\
\hline Heart attack & 6 & 4.61 & & & & \\
\hline Deep vein thrombosis & 5 & 3.84 & & & & \\
\hline Knee arthritis & 3 & 2.30 & & & 3 & \\
\hline
\end{tabular}

increased from $14(10.76 \%)$ to $18(13.84 \%)$. In 16 patients $(12.3 \%)$ after LSG esophagitis was diagnosed while preoperatively it was visible in 12 patients $(9.23 \%)$ (Table 5).

The reduction in frequency of occurrence of metabolic syndrome in obese patients after LSG is presented in Fig. 3. Statistical analysis of obtained results proved that 1 year after sleeve gastrectomy the amount of patients with possible metabolic syndrome (the occurrence of at least three criteria of metabolic syndrome according to IDF) decreased in 61 patients $(53.08 \%)$ which is $46.92 \%$ of all patients with metabolic syndrome after LSG. Six months from the surgery, the amount of patients with five criteria of metabolic syndrome decreased to about $75 \%$. After 1 year, none of the patients met five criteria of metabolic syndrome (before the surgery it was 32 patients) (Fig. 7).

\section{Discussion}

Metabolic syndrome as a collection of correlating risk factors of diabetes and cardiovascular diseases is recently

Table 5 Influence of LSG on GERD and esophagitis symptoms

\begin{tabular}{llrlll}
\hline & \multicolumn{2}{c}{ Before the surgery } & & \multicolumn{2}{l}{1 year after LSG } \\
\cline { 2 - 3 } \cline { 6 - 7 } & $n$ & & & $n$ & $\%$ \\
\hline GERD & 14 & $10.76 \%$ & & 18 & $13.84 \%$ \\
Esophagitis & 12 & $9.23 \%$ & & 16 & $12.30 \%$ \\
\hline
\end{tabular}

clinically and epidemiologically important because of correlation with obesity and constantly increasing number of cases. Its recognition increases five times the risk of developing type 2 diabetes and two times the risk of sclerosis, as well as their consequences-morbidity and mortality as a result of cardiovascular complications [21]. Currently, there is a trend to pay particular attention to the criteria of metabolic syndrome. In 2009, common consensus was published stating that three criteria from five

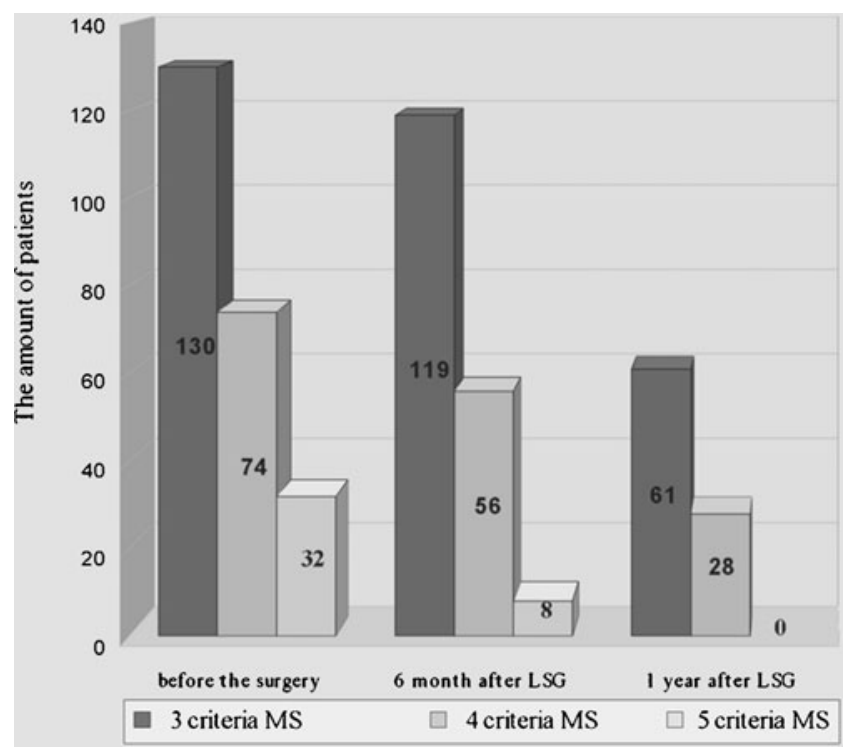

Fig. 7 The amount of patients with diagnosed metabolic syndrome (met three, four, or five criteria MS according to IDF) 6 months or 1 year after LSG 
described by the IDF are necessary to recognize metabolic syndrome: abdominal obesity (Caucasian Europeanswaist circumference $=\mathrm{M}>94 \mathrm{~cm}, \mathrm{~W}>80 \mathrm{~cm}$ ); hypertriglyceridemia $\geq 150 \mathrm{mg} / \mathrm{dl}(1.7 \mathrm{mmol} / \mathrm{l})$; low $\mathrm{HDL}$ cholesterol concentration $\mathrm{M}<40 \mathrm{mg} / \mathrm{dl}(1.03 \mathrm{mmol} / \mathrm{l})$, $\mathrm{W}<50 \mathrm{mg} / \mathrm{dl} \quad(1.29 \mathrm{mmol} / \mathrm{l})$; hypertension $\mathrm{RR} \geq 130 /$ $85 \mathrm{mmHg}$; and fasting hyperglycemia $\geq 100 \mathrm{mg} / \mathrm{dl}$ $(5.6 \mathrm{mmol} / \mathrm{l})$ or diagnosed earlier type 2 diabetes but without obesity as a main criterion [22]. According to different studies, the frequency of occurrence of metabolic syndrome is high but differs depending on the examined population and adapted criteria. According to data from the Third National Health and Nutrition Examination Survey, the occurrence of MS is determined by the criteria of NCEP ATP III, and it is estimated at $34.5 \%$ of the whole population-33.7\% in men and $35 \%$ in women. According to criteria of IDF, MS occurs in $39-40 \%$ of men and $38 \%$ of women [8]. Undoubtedly, it is a result of obesity epidemic observed all over the world in accordance with proven correlation between metabolic syndrome and excessive body mass [23]. Accumulation of visceral fat and insulin resistance are the main pathogenetic factors of MS [24]. Bariatric surgery, which is the method of choice in treatment of morbid obesity, allowed to normalize body mass, extended postoperative observations also effect favorably showed that other parameters of metabolic syndrome and cures type 2 diabetes $[25,26]$. LSG is respectively a new method among other bariatric procedures. The method is undoubtedly effective since it leads to body weight loss [27]. The results revealed after observation period shorter than 1 year indicate that body mass loss is more significant after LSG than after other bariatric procedures [28-30]. According to low perioperative risk even in patients with many co-morbidities, this procedure was firstly recommended for super obese patients (BMI $>50 \mathrm{~kg} / \mathrm{m}^{2}$ ) with high perioperative risk or as an introduction to laparoscopic Roux-en-Y gastric bypass [31]. Nowadays, it is recommended as a primary, restrictive procedure leading to effective body mass loss even in super obese patients [30]. It is highly recommended for patients with high perioperative risk connected with co-morbidities due to its short operation time (80-120 min) and minimal risk of complications. Previous observations showed that all bariatric procedures lead to body weight loss [19]. Body weight loss after LSG-as proven by 5-year observations - is effective and satisfying for patients and leads to improvement of quality of life. Our 1-year observation revealed results similar to the results of other authors [32].

Next to the favorable effects on body mass loss, LSG effectively decreases insulin resistance in accordance with improvement of glucose metabolism which results in restoration of type 2 diabetes or in lowered requisition for hypoglycemic drugs or insulin. Buchwald et al. in his metaanalysis showed the remission of type 2 diabetes in $76,8 \%$ of patients after bariatric procedure [19]. Silecchia et al. presented the restoration of insulin-dependent diabetes in $76.9 \%$ of patients and improvement in $15.4 \%$ of obese patients after LSG [33]. In another study, regression of type 2 diabetes post-LSG was shown in $27 \%$ of patients 2 months after the surgery and respectively in $63 \%$ of patients after 6 months [34]. Furthermore, it was observed that patients with T2DM lasting $<5$ years have gained better effects after surgical treatment. In our research, we have also presented the regression of diabetes at 1-year follow-up in $53.66 \%$ of patients who underwent LSG and improvement in $43.34 \%$ of patients, which confirmed the effectiveness of LSG in treatment of diabetes in obese patients with metabolic syndrome. While the increasing amount of studies confirms beneficial influence of bariatric procedures on glucose metabolism and insulin resistance, studies which recommend bariatric treatment for diabetes in patients with BMI $<30 \mathrm{~kg} / \mathrm{m}^{2}$ recently appeared. The application of LSG also significantly decreases the demand for antihypertensive drugs in accordance with normalizing blood pressure. In our research, in 20 out of 38 patients who showed improvement after bariatric surgery, one out of three antihypertensives was left and respectively in 18 patients two out of three were left. Generally, improvement regarding hypertension concerned $55.07 \%$ of patients.

Similarly to Assimakopoulos, we proved in our research the total elimination of depressive disorders in $17.94 \%$ of patients while in $25.64 \%$ we observed a significant improvement in mental state [35]. Our results showed that bariatric operation had normalized body mass in three patients $(100 \%)$ with hip osteoarthritis and in five patients $(83.3 \%)$ with knee arthritis, and at the same time allowed to qualify those patients to orthopedic surgery in order to cure the co-morbidities mentioned. LSG led, in all patients with recognized discopathy at 1-year follow-up, to regression in pain, while six patients were qualified to neurosurgical treatment. Analyzing the influence of LSG on particular co-morbidities, we observed the increase in GERD symptoms of about $3.08 \%$ and in esophagitis symptoms of $3.07 \%$. Brethauer et al. presented similar results on the effect of LSG. It is probably a result of chosen surgical technique which is changing the structure of the stomach and motor activity of the upper gastrointestinal tract [36]. Explanation of this issue needs further clinical examinations.

LSG undoubtedly improves lipid profile parameters; however, some long-term studies present that this trend is not always maintained, especially more than 2 years after the surgery. Zhang et al. also indicate that low level of HDL cholesterol and high triglycerides are the main risk factors 
for cardiovascular diseases in obese patients [37]. In our studies, 1 year after LSG, we obtained not only the decrease of LDL cholesterol, triglycerides, and total cholesterol but also the increase of HDL cholesterol; however, short-term results (before the third month after surgery) were not satisfying. Our results correlate with those published in world literature. Obtained results indicate that bariatric surgery may effectively influence dyslipidemia connected with obesity.

According to relatively short time of observation, there is a lack of research comparing the influence of other bariatric procedures (including sleeve gastrectomy) on overall range of parameters of metabolic syndrome. When sleeve gastrectomy was not taken into consideration, modified biliopancreatic diversion or gastric bypass was considered to be the best method to reduce parameters of metabolic syndrome. It elevates the value of our research which allows us to see more completely the influence of the youngest surgical techniques on parameters of metabolic syndrome.

\section{Conclusions}

According to efficiency in body mass loss presented by $\% \mathrm{EWL}$ and $\% \mathrm{EBL}$, laparoscopic sleeve gastrectomy is gaining approval as a method of obesity and metabolic syndrome treatment, although it is a relatively new procedure. It has been confirmed in our material. Basing on the literature and our own material, it can be stated that LSG is rather an easy procedure, the time of performance and hospitalization are shorter which entails lower costs, and it is more effective for patients with metabolic syndrome and for super obese patients with co-morbidities. Sleeve gastrectomy normalizes all parameters of metabolic syndrome and significantly decreases the percentage of obese patients with metabolic syndrome which is now the main cause of cardiovascular complications. It also brings beneficial effects for patients with osteoarticular disease, depressive disorders, or sleep apnea. Only in case of GERD and esophagitis LSG intensifies symptoms which should be the subject for further examination.

Bariatric surgery is currently evolving and searching for new methods to not only reduce body mass but also to make the treatment of metabolic syndrome or type 2 diabetes efficient. In the future, it will allow the adoption of proper procedure to particular therapeutic needs in patients with morbid obesity.

Conflict of interest All contributing authors declare that they have no conflicts of interest.
Open Access This article is distributed under the terms of the Creative Commons Attribution Noncommercial License which permits any noncommercial use, distribution, and reproduction in any medium, provided the original author(s) and source are credited.

\section{References}

1. Finucane MM, Stevens GA, Cowan MJ, et al. National, regional, and global trends in body-mass index since 1980: systematic analysis of health examination surveys and epidemiological studies with 960 country-years and 9.1 million participants. Lancet. 2011;377:557-67.

2. Eckel RH, Grundy SM, Zimmet PZ. The metabolic syndrome. Lancet. 2005;365:1415-28.

3. Reaven G. Role of insulin resistance in human disease. Diabetes. 1988;37:1595-607.

4. DeFronzo RA, Ferrannini E. Insulin resistance. A multifaceted syndrome responsible for NIDDM, obesity, hypertension, dyslipidemia, and atherosclerotic cardiovascular disease. Diabetes Care. 1991;14:173-94.

5. Kaplan NM. The deadly quartet. Upper-body obesity, glucose intolerance, hypertriglyceridemia, and hypertension. Arch Intern Med. 1989;149:1514-20.

6. Alberti KG, Zimmet PZ. Definition, diagnosis and classification of diabetes mellitus and its complications. Diagnosis and classification of diabetes mellitus provisional report of a WHO consultation. Diabet Med. 1998;15:539-53.

7. Grundy SM, Cleeman JI, Daniels SR, et al. Diagnosis and management of the metabolic syndrome: an American Heart Association/National Heart, Lung and Blood Institute Scientific Statement. Circulation. 2005;112:2735-52.

8. International Diabetes Federation: The IDF consensus worldwide definition of the metabolic syndrome. 2005; 1-7. (http://www.idf. org/webdata/docs/metac_syndrome_def.pdf)

9. Wyrzykowski B, Zdrojewski T, Syganowska E. Epidemiology of metabolic syndrome in Poland. Results of the WOBASZ Program. Kardiol Pol. 2005;63:S1-4.

10. Ford ES, Giles WH, Dietz WH. Prevalence of the metabolic syndrome among US adults. Findings from the Third National Health and Nutrition Examination Survey. JAMA. 2002;287:356-9.

11. Hu G, Qiao Q, Tuomilehto J, et al. Prevalence of the metabolic syndrome and its relation to all-cause and cardiovascular mortality in nondiabetic European men and women. Arch Intern Med. 2004;164:1066-76.

12. Isoma B, Almgren $P$, Tuomi $T$, et al. Cardiovascular morbidity and mortality associated with the metabolic syndrome. Diabetes Care. 2001;24:683-9.

13. Lakka HM, Laaksonen DE, Lakka TA, et al. The metabolic syndrome and total and cardiovascular disease mortality in middle-aged men. JAMA. 2002;288:2709-16.

14. Vidal J, Ibarzabal A, Romero F, et al. Type 2 diabetes mellitus and the metabolic syndrome following sleeve gastrectomy in severely obese subjects. Obes Surg. 2008;18(9):1077-82.

15. Hess DS, Hess DW. Biliopancreatic diversion with a duodenal switch. Obes Surg. 1988;8:267-82.

16. Johnston D, Dachtler J, Sue-Ling HM, et al. The Magenstrasse and Mill operation for morbid obesity. Obes Surg. 2003;13:10-6.

17. Ren CJ, Patterson E, Gagner M. Early results of laparoscopic biliopancreatic diversion with duodenal switch: a case series of 40 consecutive patients. Obes Surg. 2000;10:514-23.

18. Shi X, Karmali S, Sharma. A review of laparoscopic sleeve gastrectomy for morbid obesity. Obes Surg. 2010;20:1171-7.

19. Buchwald H, Avidor Y, Brawnwald E, et al. Bariatric surgery: a systematic review and meta-analysis. JAMA. 2004;292:1724-37. 
20. Kral JG, Naslund E. Surgical treatment of obesity. Nat Clin Pract Endocrinol Metab. 2007;3:574-83.

21. Malik S, Wong ND, Franklin SS, et al. Impact of the metabolic syndrome on mortality from coronary heart disease, cardiovascular disease, and all causes in United States adults. Circulation. 2004; 110:1245-50.

22. Alberti KG, Eckel RH, Grundy SM, et al. Harmonizing the metabolic syndrome. A joint interim statement of the International Diabetes Federation Task Force on Epidemiology and Prevention; National Heart, Lung, and Blood Institute; American Heart Association; World Heart Federation; International Atherosclerosis Society; and International Association for the Study of Obesity. Circulation. 2009;120:1640-05.

23. Jonsson S, Hedblad B, Engström G, et al. Influence of obesity on cardiovascular risk. Twenty-three-year follow-up of 22025 men from an urban Swedish population. Int J Obes Relat Metab Disord. 2002;26:1046-53.

24. Scott CL. Diagnosis, prevention, and intervention for the metabolic syndrome. Am J Cardiol. 2003;92:35-42.

25. Gracia-Solanas JA, Elia M, Aguilella V, et al. Metabolic syndrome after bariatric surgery. Results depending on the technique performed. Obes Surg. 2011;21:179-85.

26. Kwiatkowski A, Pasnik K, Stanowski E, et al. Regression of metabolic syndrome depending on type of bariatric surgery. Videosurgery and other miniinvasive techniques. 2009;4(2):53-8.

27. Karamanakos SN, Vegenas K, Kalfarenteos F, et al. Weight loss, appetite suppression, and changes in fasting and postprandial ghrelin and peptide-YY levels after Roux-en-Y gastric bypass and sleeve gastrectomy: a prospective, double blind study. Ann Surg. 2009;247(3):401-7.
28. Shi X, Karmali S, Sharma AM, et al. A review of laparoscopic sleeve gastrectomy for morbid obesity. Obes Surg. 2010;20:1171-7.

29. Nocca D, Krawczykowsky D, Bomans B, et al. A prospective multicenter study of 163 sleeve gastrectomies; results at 1 and 2 years. Obes Surg. 2008;18:560-5.

30. Himpens J, Dobbeleir J, Peeters G. Long-term results of laparoscopic sleeve gastrectomy for obesity. Ann Surg. 2010;252:319-24.

31. Clinical Issues Committee of the American Society for Metabolic and Bariatric Surgery. Sleeve gastrectomy as a bariatric procedure. Surg Obes Relat Dis. 2007;3:573-6.

32. Armstrong J, O'Malley SP. Outcomes of sleeve gastrectomy for morbid obesity. A safe and effective procedure? Int J Surg. 2010;8:69-71.

33. Silecchia G, Boru C, Pecchia A, et al. Effectiveness of laparoscopic sleeve gastrectomy. Obes Surg. 2006;16:1138-44.

34. Rosenthal R, Li X, Samuel S, et al. Effect of sleeve gastrectomy on patients with diabetes mellitus. Surg Obes Relat Dis. 2009;5:429-34.

35. Assimakopoulos K, Karaivazoglou K, Panayiotopoulos S. Bariatric surgery is associated with reduced depressive symptoms and better sexual function in obese female patients: a one-year follow-up study. Obes Surg. 2011;21(3);362-6.

36. Brethauer SA, Hammel JP, Schauer PR. Systematic review of sleeve gastrectomy as staging and primary bariatric procedure. Surg Obes Relat Dis. 2009;5(4):469-75.

37. Feng Z, Strain W, Lei W, et al. Changes in lipid profiles in morbidly obese patients after laparoscopic sleeve gastrectomy. Obes Surg. 2011;21:305-9. 